\title{
Mirror-writing and reversed repetition of digits in a right-handed patient with left basal ganglia haematoma
}

\author{
LIE-GAN CHIA, MARCEL KINSBOURNE*
}

From the Neurology Section, Veterans General Hospital, Taichung, Taiwan, and the Department of Behavioral Neurology, ${ }^{*}$ Eunice Kennedy Shriver Center, Massachusetts, USA

SUMMARY A 57 year old right-handed Chinese man sustained a left basal ganglia haemorrhage resulting in speech disorder and right hemiplegia. He mirror-wrote with his left hand and during speech recovery repeated digits in reverse sequence. The abnormal right to left directionality possibly reflected release of right basal ganglia from left-sided control.

"Mirror-writing" is a well recognised occasional finding after acute left cerebral damage as well as in young and developmentally delayed children. ${ }^{1}$ The underlying neuroanatomy is not clear, however. We report an illustrative case with a well defined and isolated left basal ganglia lesion, which shows that damage in this area is sufficient (and perhaps necessary) to cause mirror-writing and reversed repetition of digits, which has not previously been reported.

\section{Case Report}

A 57 year old right-handed Chinese man suddenly developed slurred speech and right hemiplegia. On admission to hospital the same day, his blood pressure was $160 / 110 \mathrm{~mm} \mathrm{Hg}$. He had no speech output, but good comprehension. There was right spastic hemiplegia, but no hemianopsia or alexia. CT scan revealed a haematoma with surrounding oedema in the left basal ganglia (fig 1, left). Because he could not speak, he communicated by writing. This he spontaneously did in mirror-writing (fig $2 \mathrm{~b}$ ), which he had never previously been known to do. When, on request, he tried to write in the normal direction, he found this very difficult. There were no left-handers in his family.

Ten months later, CT of the brain showed a low density area in the left basal ganglia region, resulting from absorption of the haematoma (fig 1, right). His speech was grammatical and slow, with a severe dysarthria. When he stated

Address for reprint requests: Dr Chia, Neurology Section, Veterans General Hospital, Taichung, Taiwan (400).

Received 25 March 1986 and in revised form 13 August 1986. Accepted 23 September 1986 his home address, he reversed the door number " 523 " to $\square$ \% "3-2-5." Asked to repeat other digit sequences, he also re-우 versed their order: for example, hearing or seeing "4-3-5," he repeated "5-3-4." However, he did not reverse the order of connected spoken words; given the phrase "ni-hen-hao," indicating "you are very good," he did not reverse it. His hemiplegia was improved, but he still could not use his right $ᄋ$ hand to write. He now could write normal script with his lefto hand, but some words were still mirror-written (fig 2c). He $\overrightarrow{0}$ was not observed to use tools in reverse directionality in the interim.

Two years after the onset, the brain CT scan was similar to the previous one. Although his right arm could move, the right hand remained paretic. He was still writing with the left hand. But mirror-writing was no longer evident (fig 2D), and he now found mirror-writing very difficult when asked to do it. His speech was much improved, and he now never reversed the order of spoken digits.

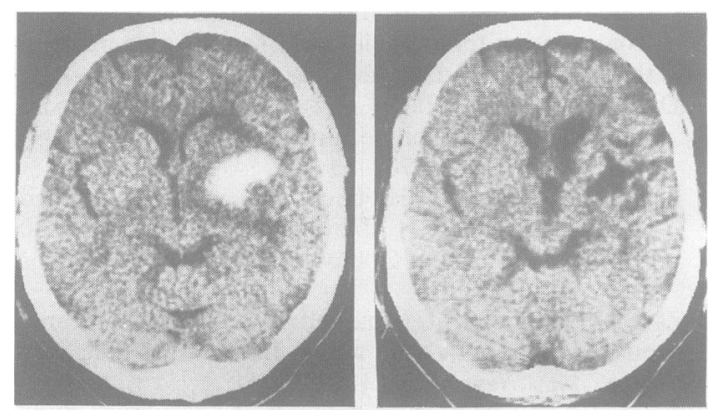

Fig 1 Left: CT showing patient's intracerebral haematoma on left basal ganglia at onset of illness. Right: CT showing a low density with absorption of haematoma on left basal ganglia ten months after onset of illness. 


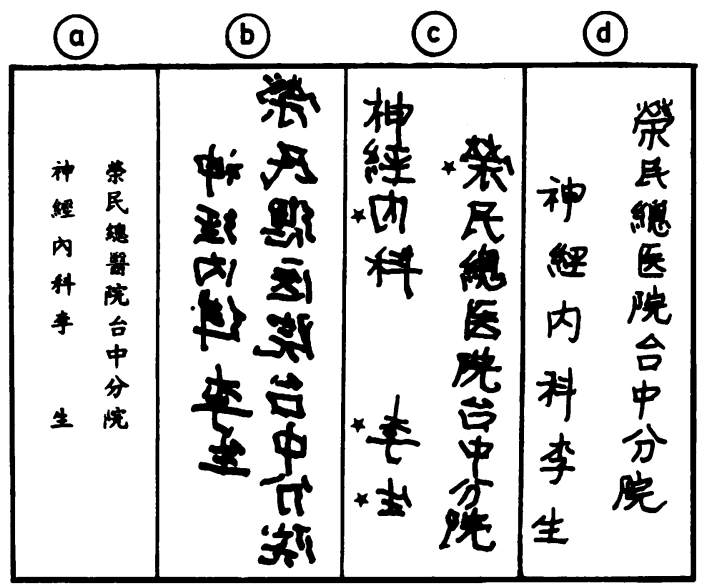

Fig 2 (A) Normal script (It means "Veterans General Hospital Taichung Neurology Section Lee San”). (B) mirror-writing, at onset of illness. (C) normal script intermixed with few mirror written words (indicated by asterisk), ten months after onset of illness. (D) normal script, two years after onset of illness.

\section{Discussion}

Individual Chinese characters are normally written from left to right and our patient reversed this direction. Their sequence, however, is vertical, and right to left, and this was unaffected. Our patient's mirrorwriting was not accompanied by any abnormality in reading. However, as Chinese is read vertically, there was no scope for mirror-reading to appear. We could find no previously reported cases of mirror-writing in Chinese after acute brain-lesions, but the case seems comparable to reported instances of mirror-writing in English following acute left cerebral damage ${ }^{1}$ such as the case of Heilman et al. ${ }^{5}$

Mirror-writing is not uncommon in young and developmentally handicapped children, perhaps particularly in the presence of left-handedness (although such individuals produce mirror-writing with either hand). Both for the developmental ${ }^{2}$ and the acquired ${ }^{3}$ instance, a theory of double representation of the motor act has been proposed. In addition to being represented in the dominant hemisphere, a representation in mirror image is hypothesised in the other hemisphere (the latter taking control of behaviour intermittently when dominance is "incomplete," or continuously for a time when the dominant hemisphere is damaged). Evidence from interocular transfer in monkeys with sectioned optic chiasm is cited in support. ${ }^{4}$ Alternatively, the mirror tendency has been viewed as a directional confusion, as illustrated in a report of a patient who also had a spatial deficit. ${ }^{5}$

Implicit in both points of view are two corollaries.
For both, our patient is a test case. (1) Had the conventional direction of action been right-to-left, that too would be subject to reversal. Inherent in Chinese script is not only left-to-right directionality for characters, which was reversed, but also right-to-left directionality for columns. This was not reversed. (2) The reversal tendency is rather nonspecific, in that any activity with a practised, unidirectional component should be affected. Indeed, associated mirror reading is often reported. But our patient did not mirror read (that is, he did not read the columns left-toright). Nor did he exhibit reversed directionality in activities of daily living.

We conclude that the above-mentioned hypotheses are not supported in the present case. His mirror writing appears to have arisen from a programming flaw specific to one component of writing. Left-to-right action was reversed, whereas right-to-left action and configuration remained intact. We attributed the selective reversal of left-to-right action to the left basal ganglia damage and predict that in cases of right basal ganglia damage the opposite element of the directional dissociation will be found, selective reversal of the right-to-left tendency for columns.

The case of closed head injury reported by Streifler and Hofman ${ }^{6}$ is consistent with this expectation (though anatomical verification is lacking). He wrote Hebrew in reverse (that is, from left to right), but maintained Western script in its left-to-right direction.

The present case offers more direct evidence for the locus of the damage than the older case reports were able to. Also, the case of Heilman et al ${ }^{5}$ was not only a left-hander (and indeterminate with respect to brain organisation), but also had previously undergone left thalamotomy. His CT scan was normal. The subcortical location of the damage in our patient perhaps supports a directional theory ${ }^{3}$ better than one invoking mirror-image engrams. ${ }^{27}$ Each striatum is known to direct action contralaterally. Rats with unilateral basal ganglia lesions circle towards the side of the lesion contralaterally, with basal ganglia stimulation ipsilaterally. ${ }^{7}$ Asymmetries are accentuated after callosal section, ${ }^{8}$ suggesting that the basal ganglia are normally in reciprocal inhibitory interaction in the control of turning tendencies. We therefore suggest that in our patient the element of left to right directionality in skilled writing performance relied on a greater left than right basal ganglia activation. After left-sided damage, activation balance reversed and so did the direction of writing. As the large haematoma was absorbed in the left basal ganglia, normally directed writing with the left hand emerged. This might be due to functional compensation by the normal tissue surrounding the lesion.

The speech disturbance induced by left basal gan- 
glia lesion in this case was of the type described as subcortical Broca's aphasia. ${ }^{9}$

The patient's unique tendency to reverse digit sequences that he was asked to repeat also fits more comfortably with a directional interpretation. The patient perhaps visualised the digit names in the lateral direction, then read them out from his imagery in the other direction. The reversal of spoken digits disappeared in parallel with his mirror writing.

The alternative theory that the writing act in toto is represented bilaterally in mirror-image ${ }^{23}$ becomes less attractive once this has to be attributed to the basal ganglia level. Disordered letter formation (apraxic agraphia) is attributed to left parietal lobe dysfunction, ${ }^{10}$ and mirror-writing is not cited as an associated finding. It seems more likely that whereas the cerebral cortex is involved in letter formation, the basal ganglia concurrently contribute the direction of writing.

We thank Dr WC Shen, Chief of Neuroradiology in VGH-Taichung, for his review of the CTs, and Dr P Alexander for his review of this paper.

\section{References}

1 Critchley M. Mirror-Writing. London: Kegan Paul, Trench, Trubner, 1928.
2 Orton ST. Specific reading disability-strephosymbolia. JAMA 1928;90:1095-9.

3 Corballis MC, Beale IL. The Psychology of Left and Right. Hillsdale, NJ: Erlbaum, 1976.

4 Noble J. Paradoxical interocular transfer of mirrorimage discriminations in the optic chiasm sectioned monkey. Brain Res 1968;10:127-51.

5 Heilman KM, Howell G, Valenstein E, Rothi L. Mirror reading and writing in association with right-left spatial disorientation. J Neurol Neurosurg Psychiatry 1980;43:774-80.

6 Streifler M, Hofman S. Sinistral mirror writing and reading after brain concussion in a bi-systemic (orientaloccidental) polyglot. Cortex 1976;12:356-64.

7 Zimmerberg B, Glick SD. Changes in side preference during unilateral electrical stimulation of the caudate nucleus in rats. Brain Res 1975;86:335-8.

8 Glick SD, Crane AM, Jerussi TP, Flusher LN, Green JP. Functional and neurochemical correlates of potentiation of striatal asymmetry by callosal section. $\mathrm{Na}$ ture 1975;254:616-7.

9 Naeser MA, Alexander MP, Helm-Estabrooks N, Levine HL, et al. Aphasia with predominantly subcortical lesion sites: description of three capsular/putaminal aphasia syndromes. Arch Neurol 1982;39:2-14.

10 Hecaen H, Angelergues R, Douzenis JA. Les agraphies. Neuropsychologia. 1963;1:179-208. 